\title{
Recurrent Peeling of Skin Following Post-Streptococcal Atypical Kawasaki Disease: A Case Report and Literature Review
}

\author{
Sam Hassan
}

\begin{abstract}
Kawasaki disease (KD) is a systemic vasculitis occurring due to collective immune mechanisms in a genetically susceptible individual, triggered by infections, though the actual cause is yet to be determined. KD is the most common cause of coronary heart disease in children. Typical diagnostic criteria are fever more than 4 days plus four of clinical criteria of cervical lymphadenopathy, skin rashes, mucus membrane redness and lip changes, non-purulent conjunctivitis, peripheral changes in palms and feet. In atypical cases three criteria with fever are enough to commence treatment and echocardiograph early. An often-reported association with KD is streptococcal infections. Skin peeling occurs in both conditions, however in streptococcal infections it occurs early while late during convalescence stage in $\mathrm{KD}$ except peeling of the genitocrural area that may occurs early. Skin peeling in the streptococcal infection is related to exotoxin while the cause of the peeling in KD is not well known; but it is likely related to the immunological pathogenesis. Another type of skin peeling that occurs recurrently following the initial attack of KD in many months is of an unknown reason. The presentation in this report is exceptional; it is for the first time reporting association of atypical KD presented with post streptococcal complications and vitamin D deficiency followed by the skin re-peeling 6 months after the patients fully resolved. Moreover, it is for the first time reporting nail changes, painful micturition due to urethral involvement and mucus membrane erythema that all resolved without treatment. The cause possibly is related to innate immune mechanism post infections and possible role for vitamin D deficiency paving the way for the post-group A streptococcal (GAS) vasculitis which is an immune response that later acted to trigger the skin peeling. Patient initially presented with significant peeling of streptococcal infections and features of KD responding to monoclonal antibody. This case highlights that clinicians need to know about recurrent peeling following KD in many months and to make the parents aware about its harmless course. It is the first report of association of post streptococcal atypical $\mathrm{KD}$ vasculitis, vitamin $\mathrm{D}$ deficiency, skin harmless post-KD skin peeling, nail changes, mucus membrane erythema and painful micturition due to urethral involvement.
\end{abstract}

Manuscript submitted December 11, 2018, accepted January 16, 2019

Department of Pediatrics, Mediclinic City Hospital, Dubai, United Arab Emirates. Email: samhassan@gmail.com

doi: https://doi.org/10.14740/ijcp319
Keywords: Kawasaki disease; Streptococcal infection; Skin peeling; Vasculitis, Kawasaki disease sequelae

\section{Introduction}

$\mathrm{KD}$ is a systemic vasculitis of an unknown etiology that seats out the way for collective immune mechanism leading to defined clinical signs and symptoms including skin manifestations. The typical presentation of KD is usually divided into three stages: an acute stage (the first 10 days) of fever for more than 4 days plus four other criteria followed by a subacute stage from week 2 to week 7 and the last stage is the convalescence stage up to 10 weeks. Skin manifestations in $\mathrm{KD}$ include polymorphic rash and BCG scar inflammation during the acute stage and skin peeling (keratolysis) particularly periungual area during the convalescent stage, however genitocrural peeling may occur during the acute stage. Peeling in the fingers occurs in the middle of the second stage (1 - 3 weeks after the resolution of fever) followed by nail changes later on during the convalescent stage. The cause of the skin peeling is not well known, unlike the streptococcal infections and the staphylococcal infections which are related to the bacterial exotoxin that affect the epidermis. Skin peeling in the streptococcal infection occurs early in the acute stage or early in the second week in cases of scarlet fever, and in the other streptococcal infections especially the palms of the hands. In these cases, skin peeling is characterized by generalized skin involvement, unlike the $\mathrm{KD}$ where it is likely confined to the periungual and genitocrural peeling. Nail changes can occur in both streptococcal infection and $\mathrm{KD}$, however nail changes were not reported before in the post KD recurrent harmless skin peeling; therefore, this is the first report of such association too. Interestingly group A streptococcal (GAS) is an often association with $\mathrm{KD}$ [1], and the exact cause of recurrent skin peeling in KD is not well known and rarely reported $[2,3]$.

GAS in particular is a well known cause of skin peeling including palms, fingers, and generalized body desquamations. GAS is gram-positive cocci which is ubiquitous and presents with variety of symptoms that may lead to significant morbidity and mortality. The prevalence of streptococcal diseases considerably decreased in the industrialized countries, but still remains a major public health concern among the developing countries. GAS usually causes two types of complications, 


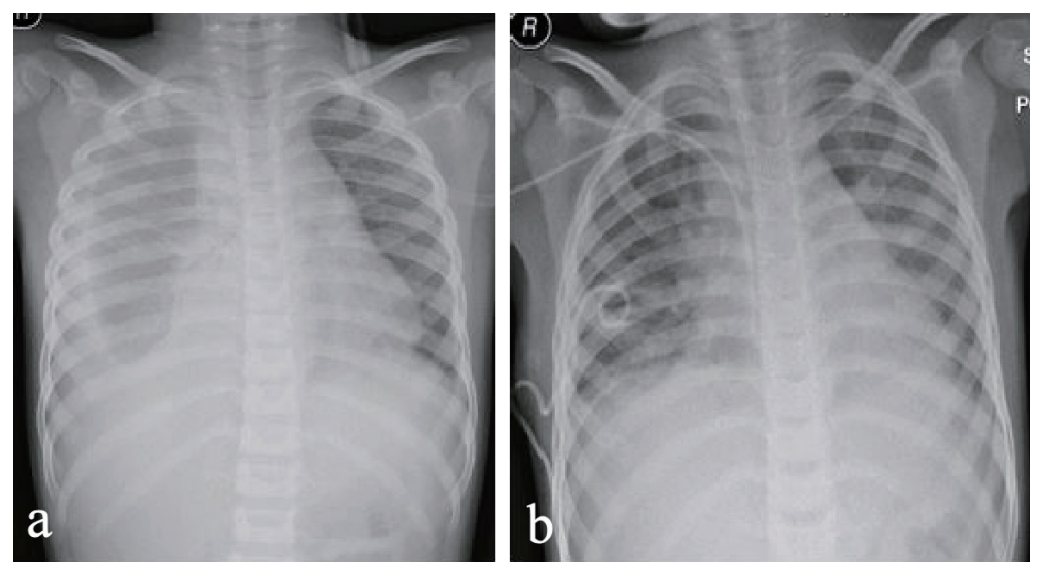

Figure 1. (a) Chest X-ray (CXR) showing right-sided pleural effusion. (b) Repeated CXR after $48 \mathrm{~h}$ showing improvement, chest drain and central line in situ.

suppurative and non-suppurative; and the suppurative complications are more common. The type of the non-suppurative complications occurs due to the effect of the bacterial pyrogen on the affected organ, such as rheumatic fever, glomerulonephritis, reactive arthritis, Kawasaki disease, pediatric autoimmune neuropsychiatric disorders and the rarely reported systemic vasculitis $[4,5]$. The non-suppurative complications arise from certain subtypes of GAS which cause an autoimmune response, molecular mimicry [6]. In this case we present for the first-time the association of post GAS compound complications including atypical $\mathrm{KD}$ vasculitis, vitamin $\mathrm{D}$ deficiency; and 6 months later the patient presented with recurrent harmless skin peeling with nail changes that is likely due to immunological activation. Such an association was not reported before, neither the nail and mucus membrane changes plus painful micturition due to urethral involvement which is reported for the first time with post KD recurrent self-limited skin peeling.

\section{Case Report}

A 5-year-old boy was referred to our tertiary teaching hospital 6 months before from another hospital for a possible nephritis due to hematuria, proteinuria, elevated protein/creatinine ratio and borderline low blood pressure. At that time he presented with a history of fever and lethargy on and off for 9 days which was responding to paracetamol; however 2 days prior to admission into the referral hospital he had poor appetite, cough, rash with fever and somnolence, which made him miss 2 days from school. He had been admitted for 2 days and was given ceftriaxone $50 \mathrm{mg} / \mathrm{kg}$ per day, once a day before referral. The patient was healthy before with no significant family history or past history. He had one elder brother who is healthy and they live with both parents. The father is a pilot of European nationality and the family just returned from a holiday in France and the USA. There is no exposure to environmental factors or animals, and he was fully immunized. Upon arrival his temperature was $38.8{ }^{\circ} \mathrm{C}$, pulse rate $147 \mathrm{bpm}$, respiratory rate $25 / \mathrm{min}$, blood pressure $90 / 52 \mathrm{~mm} \mathrm{Hg}, \mathrm{SaO}_{2} 85 \%$ in air, and capillary refill time $4 \mathrm{~s}$. He was given intravenous (IV) fluid bolus $20 \mathrm{~mL} / \mathrm{kg}$ normal saline and 5\% albumin $100 \mathrm{~mL}$ over 1 hour with high flow oxygen and admitted initially to the PICU. The patient's neurological examination was normal. He had sandpaper like rash all over the body and normal mucus membrane and conjunctiva with no enlarged lymph nodes. The air entry on the right side was poor and the chest X-ray (CXR) showed pleural effusion which was confirmed by ultrasound (US) scan that resolved after US-guided needle aspiration and chest drain (Fig. 1). Exudative fluid $350 \mathrm{~mL}$ was drained out which was negative for bacteria, tuberculosis (TB), cytology, and fungal infection. He was given IV ceftriaxone antibiotics $50 \mathrm{mg} / \mathrm{kg}$ per day (total of 7 days) and oral azithromycin 10 $\mathrm{mg} / \mathrm{kg}$ per day (stopped after 5 days) before admission for 1 day, and started empirical antibiotics as before and vancomycin $15 \mathrm{mg} / \mathrm{kg}$ per day (for 7 days) was added. In view of no response and despite the chest US showing full recovery from the empyema, the patient continued to spike high fever after $48 \mathrm{~h}$, so clindamycin $10 \mathrm{mg} / \mathrm{kg}$ per day was added (6 days). Tamiflu (Oseltamivir) $45 \mathrm{mg}$ twice a day was also given for 5 days in view of that the H1N1 was positive in the respiratory panel PCR swab. The patients then showed dry lips, mucus membrane congestions and mild conjunctivitis, but no lymph nodes involved. Patient remained febrile, not looking well, not toxic or irritable, but fully conscious with normal neurological examination.

The initial investigations showed an evidence of nephritis, deranged liver enzymes, and increased inflammatory markers (Tables 1, 2). The child remained unwell with persistent fever, and blood tests for infection screens, rheumatoid screen, oncology bone marrow (histochemistry, cytology, Fish test chromosome analysis), such as ANCA, ANCA-P, Rheumatoid factor, anti-DNA antibodies, ANA antibodies, Coombs test, coagulation screen, blood culture, urine culture, cerebrospinal fluid (CSF), stool culture, stool for GIT PCR multiplex panel screen, Dengue fever, calcium, alkaline phosphatase, phosphorous, magnesium, serum ferritin, HIV screen, Zika virus screen, CMV, EBV, adenovirus, parvovirus, leukocyte dehydrogenase, uric acid, TB Gold Quantiferon, Mantoux test, monospot test, hepatitis A and B serology, creatine kinase, haptoglobulin, Le- 
Table 1. Blood Results While Admitted (Arrows Indicate Repeated Results Days Apart)

\begin{tabular}{ll}
\hline C-reactive protein $(\mathrm{mg} / \mathrm{dL})$ & $348 \rightarrow 228 \rightarrow 156 \rightarrow 75 \rightarrow 14.5$ \\
ESR $(\mathrm{mm} / \mathrm{h})$ & $67 \rightarrow>150 \rightarrow 140 \rightarrow 48$ \\
White blood cell count $\left(\times 10^{3} / \mu \mathrm{L}\right)$ & $8.1 \rightarrow 41 \rightarrow 27.8 \rightarrow 12 \rightarrow 11$ \\
Complement C3 $(\mathrm{g} / \mathrm{L})$ & $0.45 \rightarrow 1.67$ \\
Complement C4 $(\mathrm{g} / \mathrm{L})$ & $0.05 \rightarrow 0.22$ \\
ALT $(\mathrm{IU} / \mathrm{L})$ & $27 \rightarrow 67 \rightarrow 28$ \\
AST $(\mathrm{IU} / \mathrm{L})$ & $48 \rightarrow 38 \rightarrow 43$ \\
Platelets $\left(\times 10^{3} / \mu \mathrm{L}\right)$ & $99 \rightarrow 1,001 \rightarrow 832 \rightarrow 664$ \\
ASO titre $(\mathrm{IU} / \mathrm{mL})$ & $<50 \rightarrow 1,825 \rightarrow 830$ \\
Hemoglobin $(\mathrm{g} / \mathrm{dL})$ & $13.4 \rightarrow 9.1 \rightarrow 5.7 \rightarrow 8.2$ \\
D-dimer $(\mu \mathrm{g} / \mathrm{mL} \mathrm{FEU})$ & $13.7 \rightarrow 12.5$ \\
Fibrinogen $(\mathrm{mg} / \mathrm{dL})$ & $638 \rightarrow 497 \rightarrow 415$ \\
Anti-DNase B $(\mathrm{U} / \mathrm{mL})$ & $1,310 \rightarrow 1,280 \rightarrow 886$ \\
\hline
\end{tabular}

gionella antigen in urine, streptococcal pneumonia antigen in urine, mycoplasma serology, H. pylori serology and stool, vitamin B12, zinc level, Rubella serology, measles IgM, Borrelia serology, malaria screen, echocardiography, and renal biopsy were all normal. The positive results are as shown in Tables $1-3$, and his full blood count on admission was: white cell count $8.1 \times 10^{3} / \mu \mathrm{L}$, red blood cells $3.86 \times 10^{6} / \mu \mathrm{L}$, hemoglobin $10.6 \mathrm{~g} / \mathrm{dL}$, platelet $99 \times 10^{3} / \mu \mathrm{L}$, neutrophils $7.09 \times 10^{3} / \mu \mathrm{L}$, lymphocytes $0.49 \times 10^{3} / \mu \mathrm{L}$, monocytes $0.29 \times 10^{3} / \mu \mathrm{L}$, eosinophils $0.21 \times 10^{3} / \mu \mathrm{L}$, and basophils $0.02 \times 10^{3} / \mu \mathrm{L}$. All cultures including blood, urine, CSF, swabs, and others were done under full aspect procedures according to local guidelines and both aerobic and anaerobic methods and medias applied were appropriate.

The scarlet like skin rash started to peel including the lips (Fig .2). A diagnosis of atypical KD was considered while the echocardiographs only showed trivial mitral regurgitation. The patient was given two doses of intravenous immunoglobulin (IVIG) ( $2 \mathrm{~g} / \mathrm{kg}$ each time) alongside with methylprednisolone $(20 \mathrm{mg} / \mathrm{kg})$ for which he had no response after $48 \mathrm{~h}$ and his inflammatory markers remained high. The antibiotics were then

Table 2. Blood Results 2 Weeks After Discharge (Arrows Indicate Repeated Results 6 Months Later)

\begin{tabular}{ll}
\hline C-reactive protein $(\mathrm{mg} / \mathrm{dL})$ & $2.2 \rightarrow 1.8$ \\
ESR $(\mathrm{mm} / \mathrm{h})$ & $48 \rightarrow 7$ \\
White blood cell count $\left(\times 10^{3} / \mu \mathrm{L}\right)$ & $10.7 \rightarrow 7.1$ \\
ALT $(\mathrm{IU} / \mathrm{L})$ & $28 \rightarrow 8$ \\
AST $(\mathrm{IU} / \mathrm{L})$ & $43 \rightarrow 24$ \\
Platelets $\left(\times 10^{3} / \mu \mathrm{L}\right)$ & $410 \rightarrow 299$ \\
ASO titre $(\mathrm{IU} / \mathrm{mL})$ & $700 \rightarrow 268$ \\
Hemoglobin $(\mathrm{g} / \mathrm{dL})$ & $10.5 \rightarrow 12$ \\
D-dimer $(\mu \mathrm{g} / \mathrm{mL}$ FEU) & $8.5 \rightarrow 0.57$ \\
Fibrinogen $(\mathrm{mg} / \mathrm{dL})$ & $359 \rightarrow 308$ \\
Anti-DNase $\mathrm{B}(\mathrm{U} / \mathrm{mL})$ & $886 \rightarrow 150$ \\
\hline
\end{tabular}

stopped too.

The ASOT was less than $50 \mathrm{IU} / \mathrm{mL}$ at the time of admission and the repeated test after 10 days significantly increased to $1,834 \mathrm{IU} / \mathrm{mL}$ while the anti-DNase-B strep antibodies was high to $1,310 \mathrm{U} / \mathrm{mL}$ (normal values: 0 - 70). Serum fibrinogen and the D-dimer were both increased, suggesting endothelial damage and systemic vasculitis [4].

After 10 days of empirical antibiotics, no response to IVIG and the results suggesting vasculitis (atypical post-streptococcal $\mathrm{KD}$ ), the patients was given infliximab IV infusion (5 $\mathrm{mg} / \mathrm{kg}$ over $3 \mathrm{~h}$ ) with Chlorohistol IV, $1 \mathrm{mg} / \mathrm{kg}$ given before. The patients then had dramatic improvement clinically, fever subsided for the first time back to normal within few hours of the infusion and FBC, liver enzymes, urine test, C-reactive protein (CRP), erythrocyte sedimentation rate (ESR), fibrinogen, D-dimer, and platelets were all improved and normalized between 3-week to 6-month follow-up. The patient was followed for over a year. The platelets started to increase there-

Table 3. Blood Results During the Recurrent Skin Peeling (6 Months After the Acute Stage)

\begin{tabular}{ll}
\hline C-reactive protein $(\mathrm{mg} / \mathrm{dL})$ & 14 \\
ESR $(\mathrm{mm} / \mathrm{h})$ & 15 \\
White blood cell count $\left(\times 10^{3} / \mu \mathrm{L}\right)$ & 15 \\
Complement $\mathrm{C} 3(\mathrm{~g} / \mathrm{L})$ & 0.45 \\
Complement C4 $(\mathrm{g} / \mathrm{L})$ & 0.05 \\
ALT $(\mathrm{IU} / \mathrm{L})$ & 18 \\
AST $(\mathrm{IU} / \mathrm{L})$ & 23 \\
Platelets $\left(\times 10^{3} / \mu \mathrm{L}\right)$ & 455 \\
ASO titre $(\mathrm{IU} / \mathrm{mL})$ & 116 \\
Hemoglobin $(\mathrm{g} / \mathrm{dL})$ & 12.6 \\
D-dimer $(\mu \mathrm{g} / \mathrm{mL} \mathrm{FEU})$ & 0.35 \\
Fibrinogen $(\mathrm{mg} / \mathrm{dL})$ & 359 \\
Anti-DNase B $(\mathrm{U} / \mathrm{mL})$ & 153 \\
\hline
\end{tabular}



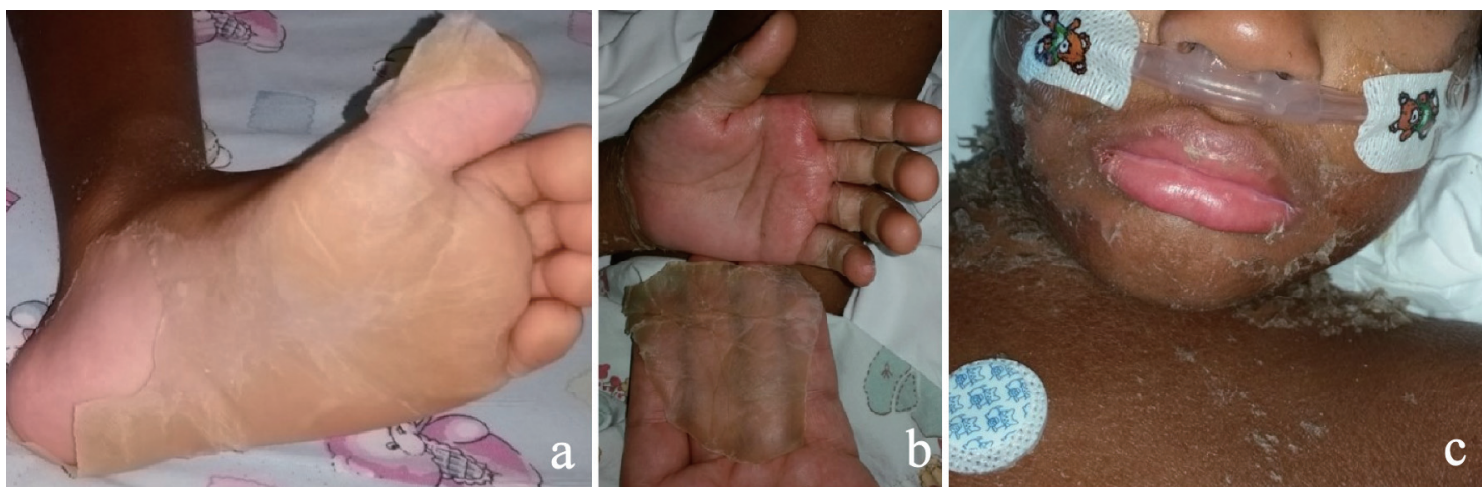

Figure 2. Peeling of the skin during the initial presentation (6 months before).

after before it was normalized after about 6 months of followup. The patient was on aspirin antiplatelet dose $(5 \mathrm{mg} / \mathrm{kg} / \mathrm{dose}$, OD) which was stopped on normal echocardiographs after 4 months of follow-up.

Before the infliximab the patient's $\mathrm{Hb}$ was dropping from $13.4 \mathrm{~g} / \mathrm{dL}$ to $5.7 \mathrm{~g} / \mathrm{dL}$. Blood transfusion was declined by the parents and hence erythropoietin was used subcutaneously (50 $\mathrm{U} / \mathrm{kg}$ three times per week). Erythropoietin was introduced at the time of the infliximab infusion and the $\mathrm{Hb}$ increased to $6 \mathrm{~g} /$ $\mathrm{dL}$ and normalized later on follow-up.

Interestingly the patient had sever vitamin D deficiency $(8.8 \mathrm{ng} / \mathrm{mL})$, he was then treated with 10,000 IU orally followed by 2,000 IU daily and reduced to 400 IU daily after normalization of blood concentration of vitamin D3 which was maintained on $35 \mathrm{ng} / \mathrm{mL}$.

On follow-up the patient recovered fully and all his blood tests normalized after 3 - 6 months (the last figures in Table 2). After 6 months of full improvements the patients remained well apart from chicken pox rash that resolved fully. Nine months after the initial episode, he presented with sudden generalized peeling of skin, periungual peeling, nail changes and mild redness of the tongue and mucus membrane (Fig. 3), while he was active, well and no constitutional symptoms and attending school normally. The peeling was prominent in the genital area causing painful urination on the tip of the urethral meatus which was resolved to Fucicort cream. His urine analysis and culture were normal. He had no fever but only very mild upper respiratory tract symptoms that resolved over 2 3 days. All his blood tests (Table 3) were normal. Nasal and throat swabs for viral PCR respiratory panel and streptococcal swab were negative apart from enterovirus positive. The $\mathrm{IgE}$ was $180 \mathrm{IU} / \mathrm{L}$ which is below the cut-point for allergy for age [7]. Two echocardiographs 1 week apart were normal. The patient remained well and active. The skin peeling resolved totally after 7 days without any complications but he had new nails developing on the base of the damaged one (Fig. 2). On follow-up for another 6 months he remained well and his skin peeling fully resolved.

\section{Discussion}

This case is the first to report recurrent skin peeling following $\mathrm{KD}$ that presented with nail changes, mucus membrane involvement and pain in micturition due to peeling in urethral orifice. Likewise is the initial atypical presentation of post streptococcal atypical KD vasculitis in association with vitamin D deficiency and post streptococcal complications.

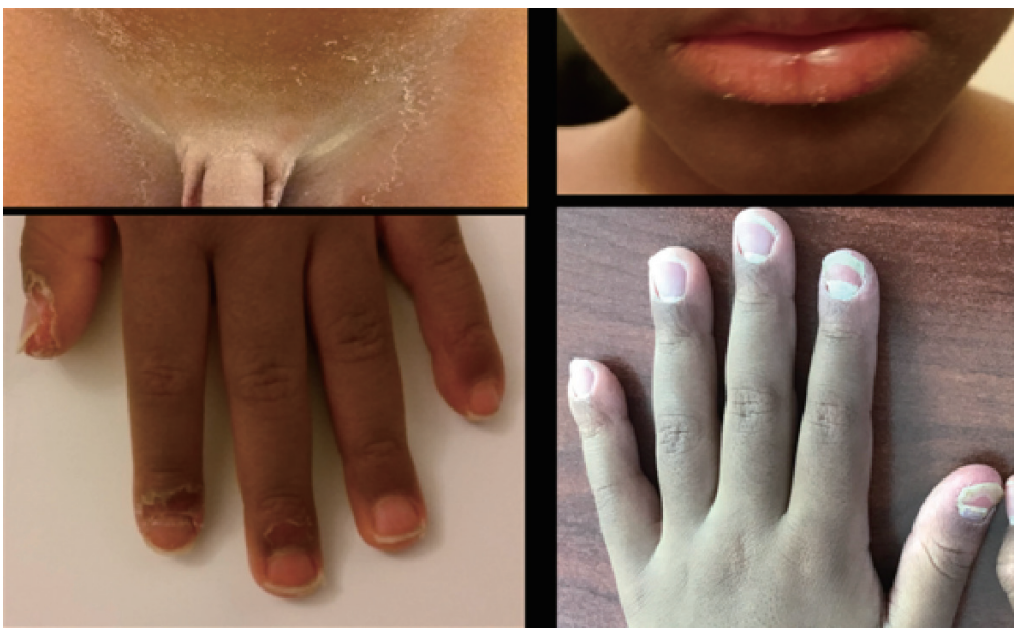

Figure 3. Recurrent peeling of the skin and nail damage 6 months later. 
Table 4. IgG Subclasses (Normal Reference Values) (Arrows Show Repeated Levels and the Last Two Were 3 and 6 Months of Follow-Up)

\begin{tabular}{ll}
\hline $\operatorname{Ig~G} 1(\mathrm{mg} / \mathrm{dL})$ & $3,276 \rightarrow 2,466 \rightarrow 1,900 \rightarrow 683(306-794)$ \\
$\mathrm{Ig} \mathrm{G} 2(\mathrm{mg} / \mathrm{dL})$ & $1,038 \rightarrow 529 \rightarrow 376 \rightarrow 106(68-327)$ \\
$\mathrm{Ig} \mathrm{G} 3(\mathrm{mg} / \mathrm{dL})$ & $>213 \rightarrow>213 \rightarrow 212 \rightarrow 81(16-94)$ \\
$\mathrm{Ig} \mathrm{G} 4(\mathrm{mg} / \mathrm{dL})$ & $34 \rightarrow 26 \rightarrow 17 \rightarrow 3(2-96)$
\end{tabular}

The patient was initially admitted due to compound poststreptococcal complications and fulfilled the clinical criteria of atypical KD that responded only to biological treatment. Other causes such as infectious, rheumatological, oncological and suspected nephritis were rolled out by investigations. He had scarlet fever like rash on admission, however the patient's dark skin makes the diagnosis of the SF clinically challenging especially on the face of normal ASO titer and throat swab cultures. Repeated tests showed strong evidence of streptococcal infection (ASOT sero-conversion from less than 50 to 1,840 $\mathrm{IU} / \mathrm{mL}$, and anti-DNase B was $1,325 \mathrm{U} / \mathrm{mL}$ ). The combined elevation of both revealed a sensitivity of $95 \%$ and specificity of $98 \%$ [8], and with the sero-conversion make the diagnosis of streptococcal infections even more reliable [9]. The rapid antigen throat swab test for streptococci can be negative in the first week of infection so as not always reliable in the diagnosis of SF [10], and seroconversion then was required to support the diagnosis.

The patient's vitamin D level was extremely low and the IgG subclasses 1,2 , and 3 were very high (Table 4 ). There were evidence of endothelial injury (vasculitis) namely increased D-dimer and fibrinogen level.

It is likely that the very low vitamin D might have been for long time paving the way for multiple complications following GAS. The nonresponse to the conventional treatment and the dramatic improvement to the biological treatment signified the disturbed immune system that resulted from very low vitamin D. He was discharged home $72 \mathrm{~h}$ after infliximab and resolved fully after 3 weeks on follow-up until 9 months later when he had generalized skin peeling, mildly red tongue, nail changes, pain on the tip of urethral meatus on urination and mild URTI enterovirus infection. At his time, his blood tests return back to normal including the ASOT and acute response proteins (CRP, ESR, and platelet).

It has been shown that vitamin $\mathrm{D}$ deficiency increases the susceptibility and hence the complications of infections [1114]. A vitamin D level of less than $30 \mathrm{ng} / \mathrm{mL}$ is associated with different bacterial and viral infections [15-21]. Vitamin D is an innate and local immune-modulatory regulator which is produced by the immune cells. It inhibits B and T cell proliferation so as the immunoglobulin production [22-23], subsequently decreasing the inflammatory cytokines (IL-17 and 21) and increasing the anti-inflammatory cytokines like IL- 10. It also inhibits monocytes, dendritic cells (DC) and TNF- $\alpha$. Interestingly to note is that the patient's monocytes count was high. The DC is important in self-tolerance immune system, in that when the immature DC presents the self-antigen, it produces tolerance in reverse to the same antigen presented by mature DC. Self-antigen resultant from infection or cell death is abundant in the body. Vitamin D increases self-antigen tolerance by inhibiting maturation of DC. Vasculitis like the one happening in $\mathrm{KD}$ is the one of the resultant complications of this autoimmune response to infections [24]. With such immune derangement, GAS infections and complications accentuated it, and may switch off immune responses that caused skin peeling and remained inactive to be activated again by infections like viral or bacterial infections, such as staph infection and enterovirus in this case [25]. It is therefore, logical to assume that the severity of the complications following the GAS infection and the immunological response that only responded to monoclonal antibody treatment may be due to the long-standing vitamin D deficiency. The same mechanism is more likely played a role in the skin peeling initially and later on when the patient presented with self-limiting peeling.

In GAS, there are several immune mechanisms that may be operable in post streptococcal syndromes including skin peeling, such as antibody-directed molecular mimicry [26-27] and possible super antigen stimulation of T cells. GAS produces pyrogenic exotoxins which is responsible for the activation of T cells and known to damage the plasma membranes of blood capillaries under the skin, hence the rash that followed by the peeling. There have been at least 13 types of the pyrogenic exotoxins implicated in different tissue and skin inflammations [28-29]. The commonest are streptococcal pyrogenic exotoxin A (SpeA), SpeB and SpeC. SpeA and $\mathrm{SpeC}$ bind and activate the $\mathrm{T}$ cells which then produce pro-inflammatory cytokines and chemokines. This binding happens with low affinity and is nonspecific; hence it allows the superantigens $\mathrm{A}$ and $\mathrm{C}$ to activate many $\mathrm{T}$ cells reaching up to $50 \%$ of the body $\mathrm{T}$ cells. Vitamin $\mathrm{D}$ deficiency in this case makes more $\mathrm{T}$ cells available for the action of the GAS super-antigen. SpeB degrades immunoglobulins and cytokines, as well as through cleavage of $\mathrm{C} 3 \mathrm{~b}$, inhibiting recruitment of phagocytic cells and the complement activation pathway. This results in decreased inflammation and neutrophil levels around the site of infection, preventing clearance and phagocytosis and promoting the survival of GAS pyogenes [28].

Furthermore, the levels of the patient's IgG subclasses 1,2 and 3 were very high. This is likely due to the protracted scarcity of the action of vitamin D on the B cells which ended by escalating the immune-infectious consequences of GAS [22]. The normalization of the IgG subclasses blood levels (Table 4) ensued after correction of vitamin D status. The IgG subclasses play an important role in the development of vasculitis by activating the cytokine-primed neutrophils within the vasculature and the complement system leading to rapid intensification of inflammation and recruitment of monocytes causing endothelial damage and consequential vasculitis of the skin manifestations. It is known that in normal individuals the human $\operatorname{IgG}$ antibodies provide multiple protective mechanisms through their multifunctional adapted molecule, whereas the Fab region binds to the antigens and the FC region to the multiple protective effectors ligands. Potential pathogens such as streptococci evolve strategies to frustrate and/or evade these protective mechanisms [30]. The whole process of such an immunological reaction leads to the characteristic clinical features, part of which is keratolysis (skin peeling). 
It is the extravagant action of GAS due to vitamin D deficiency which leads to the compound complications and immunological reaction. The patient including the keratolysis dramatically responded to infliximab but not to the IV immunoglobulin, which indicated these complex inflammatory pathways that were made worse by vitamin D deficiency [31-32].

The skin itself is a complex organ that serves as an arena for a wide variety of inflammatory activities including postinfectious immunological processes [33]. It is the largest organ of the body and a continuum for a large part of the immune system. Memory T cells may reside for long time in the skin to be reactivated when there is other infections in future. $T$ lymphocytes subsets, B lymphocytes, cytokines, interleukins, immunoglobulins, and other complex immune response dwell in the skin to be related with different immune mechanisms, some of which are responsible for skin peeling [34]. The exact mechanism of skin peeling that occurs after many illnesses including post vasculitis and KD is not very well known. In this patient the complex activation of the immune system that seats out by two known keratolysing conditions, expanded by vitamin $\mathrm{D}$ deficiency that is a known immunomodulator, likely activated multiple skin immune memory complexes including $\mathrm{T}$ cell. This immune response became latent and reactivated by other minor infections leading to recurrent but harmless peeling months after the initial infection. The recognition of this process is very important to avoid unwarranted anxiety and investigations in post KD recurrent skin peeling that have also to be differentiated from the recurrence of KD itself. Clinicians should be aware of this condition and make parents aware too following the acute stage of KD or post-streptococcal vasculitis. This harmless skin peeling may occur several times preceded by infections up to 7 years following the resolving of the initial episode $[2,3]$. It is likely that the recurrence of skin peeling following KD could happen more if it is associated with streptococcal infection and or vitamin D deficiency. It is therefore recommended to investigate for streptococcal infections ideally for seroconversion if the ASOT is normal in the first week when KD was suspected as well as vitamin D level. Both KD and GAS infection may switch multiple skin immunological mechanisms that lead to peeling not only in the acute stage but later on when the dormant immunological pathway reactivated by other infections like viral illness. In fact the initial skin peeling in this patients happened during the fever stage was likely due to streptococcal infection then amplified by KD sequelae and vitamin D deficiency; while the recurrent peeling was triggered by respiratory enterovirus infection. The patient was not suffering from any skin peeling before the initial episode of post streptococcal KD vasculitis.

\section{Conclusions}

This case report showed that the recurrent skin peeling following post-streptococcal KD vasculitis happened many months after the initial disease subsided and is harmless; however it should be differentiated from recurrent KD. It is likely an immunological process that remained dormant to be reactivated by minor infections later on. It may also be escalated by vitamin $\mathrm{D}$ deficiency. Parents should be warranted about the two conditions following KD namely the recurrence of the $\mathrm{KD}$ itself and the recurrent harmless skin peeling that may be triggered by minor infections. In this case, the associated nail damage and urethral pain during urination have not been reported before, neither the vitamin D deficiency in the initial attack.

\section{Acknowledgments}

The authors are grateful to the parents of the child who allowed to publish this case and all professionals and departments involved in the management.

\section{Conflict of Interest}

The authors declare that there is no conflict of interest regarding the publication of this paper.

\section{References}

1. Benseler SM, McCrindle BW, Silverman ED, Tyrrell PN, Wong J, Yeung RS. Infections and Kawasaki disease: implications for coronary artery outcome. Pediatrics. 2005;116(6):e760-766.

2. Michie C, Kinsler V, Tulloh R, Davidson S. Recurrent skin peeling following Kawasaki disease. Arch Dis Child. 2000;83(4):353-355.

3. Parmar RC, Somale A, Bavdekar SB, Muranjan MN. Incomplete Kawasaki disease with recurrent skin peeling: a case report with the review of literature. J Postgrad Med. 2003;49(1):72-74.

4. Martins AL, Figueiredo AE, Brito MJ. Vasculitis, a rare presentation of a post-streptococcal syndrome. Clin Res Infect Dis. 2015;2(1):1011

5. Ivory D, Folzenlogen D. Post streptococcal syndromes, a rheumatologist perspective. The Internet J of Rheumatol. 2009;6:2.

6. Dennis K, Anthony F, Stephen H, Dan L, Larry J, Joseph L. Harrison's principles of internal medicine. 19th edition. McGraw Hill Education. 2015.

7. Martins TB, Bandhauer ME, Bunker AM, Roberts WL, Hill HR. New childhood and adult reference intervals for total IgE. J Allergy Clin Immunol. 2014;133(2):589-591.

8. Blyth CC, Robertson PW. Anti-streptococcal antibodies in the diagnosis of acute and post-streptococcal disease: streptokinase versus streptolysin $\mathrm{O}$ and deoxyribonuclease B. Pathology. 2006;38(2):152-156.

9. Johnson DR, Kurlan R, Leckman J, Kaplan EL. The human immune response to streptococcal extracellular antigens: clinical, diagnostic, and potential pathogenetic implications. Clin Infect Dis. 2010;50(4):481-490.

10. Pace B. JAMA patient page. Strep throat. JAMA. 2000;284(22):2964.

11. Sabetta JR, DePetrillo P, Cipriani RJ, Smardin J, Burns LA, Landry ML. Serum 25-hydroxyvitamin d and the 
incidence of acute viral respiratory tract infections in healthy adults. PLoS One. 2010;5(6):e11088.

12. Berry DJ, Hesketh K, Power C, Hypponen E. Vitamin D status has a linear association with seasonal infections and lung function in British adults. Br J Nutr. 2011;106(9):1433-1440.

13. Mulrennan S, Knuiman M, Walsh JP, Hui J, Hunter M, Divitini M, Zhu K, et al. Vitamin D and respiratory health in the Busselton Healthy Ageing Study. Respirology. 2018;23(6):576-582.

14. Li W, Cheng X, Guo L, Li H, Sun C, Cui X, Zhang Q, et al. Association between serum 25-hydroxyvitamin D concentration and pulmonary infection in children. Medicine (Baltimore). 2018;97(1):e9060.

15. Bikle D. Nonclassic actions of vitamin D. J Clin Endocrinol Metab. 2009;94(1):26-34.

16. Ginde AA, Mansbach JM, Camargo CA, Jr. Association between serum 25-hydroxyvitamin D level and upper respiratory tract infection in the Third National Health and Nutrition Examination Survey. Arch Intern Med. 2009;169(4):384-390.

17. Laaksi I, Ruohola JP, Tuohimaa P, Auvinen A, Haataja R, Pihlajamaki H, Ylikomi T. An association of serum vitamin D concentrations $<40 \mathrm{nmol} / \mathrm{L}$ with acute respiratory tract infection in young Finnish men. Am J Clin Nutr. 2007;86(3):714-717.

18. Cannell JJ, Vieth R, Umhau JC, Holick MF, Grant WB, Madronich S, Garland CF, et al. Epidemic influenza and vitamin D. Epidemiol Infect. 2006;134(6):1129-1140.

19. Bodnar LM, Krohn MA, Simhan HN. Maternal vitamin $\mathrm{D}$ deficiency is associated with bacterial vaginosis in the first trimester of pregnancy. J Nutr. 2009;139(6):11571161.

20. Villamor E. A potential role for vitamin D on HIV infection? Nutr Rev. 2006;64(5 Pt 1):226-233.

21. Rodriguez M, Daniels B, Gunawardene S, Robbins GK. High frequency of vitamin D deficiency in ambulatory HIV-Positive patients. AIDS Res Hum Retroviruses. 2009;25(1):9-14.

22. Lemire JM, Adams JS, Sakai R, Jordan SC. 1 alpha,25dihydroxyvitamin D3 suppresses proliferation and immunoglobulin production by normal human peripheral blood mononuclear cells. J Clin Invest. 1984;74(2):657-661.

23. Almerighi C, Sinistro A, Cavazza A, Ciaprini C, Rocchi G, Bergamini A. 1Alpha,25-dihydroxyvitamin D3 inhibits CD40L-induced pro-inflammatory and immunomodulatory activity in human monocytes. Cytokine. 2009;45(3):190-197.

24. Aranow C. Vitamin D and the immune system. J Investig Med. 2011;59(6):881-886.

25. Quinn A, Kosanke S, Fischetti VA, Factor SM, Cunningham MW. Induction of autoimmune valvular heart disease by recombinant streptococcal $\mathrm{m}$ protein. Infect Immun. 2001;69(6):4072-4078.

26. Martins TB, Veasy LG, Hill HR. Antibody responses to group A streptococcal infections in acute rheumatic fever. Pediatr Infect Dis J. 2006;25(9):832-837.

27. Davison SC, Allen MH, Mallon E, Barker JN. Contrasting patterns of streptococcal superantigen-induced $\mathrm{T}$ cell proliferation in guttate vs. chronic plaque psoriasis. Br J Dermatol. 2001;145(2):245-251.

28. Knoll H, Sramek J, Vrbova K, Gerlach D, Reichardt W, Kohler W. Scarlet fever and types of erythrogenic toxins produced by the infecting streptococcal strains. Zentralbl Bakteriol. 1991;276(1):94-106.

29. Brosnahan AJ, Schlievert PM. Gram-positive bacterial superantigen outside-in signaling causes toxic shock syndrome. FEBS J. 2011;278(23):4649-4667.

30. Holland M, Takada K, Okumoto T, Takahashi N, Kato K, Adu D, Ben-Smith A, et al. Hypogalactosylation of serum IgG in patients with ANCA-associated systemic vasculitis. Clin Exp Immunol. 2002;129(1):183-190.

31. Maini RN, Feldmann M. How does infliximab work in rheumatoid arthritis? Arthritis Res. 2002;(Suppl 2):S2228.

32. Schafranski MD, Campanari GD. Infliximab for idiopathic deep cutaneous vasculitis refractory to cyclophosphamide. Int J Vasc Med. 2010;2010:951850.

33. Mann E R, Smith KM, Bernardo D, et al. Review: skin and the immune system. J Clin Exp Dermatol Res. 2012;:S2:003.

34. Richmond JM, Harris JE. Immunology and skin in health and disease. Cold Spring Harb Perspect Med. 2014;4(12):a015339. 